\title{
The Deep Roots of Addiction: A Comparative Perspective
}

\author{
Nabil Karnib Moira J.van Staaden \\ Department of Biological Sciences, JP Scott Center for Neuroscience, Mind and Behavior, Bowling Green State \\ University, Bowling Green, $\mathrm{OH}$, USA
}

\section{Keywords}

Addiction · Reward · Evolution · Nicotine · Homology common underlying cellular and molecular mechanisms that advocate for the adoption of a phylogenetic view of addiction.

(c) 2021 S. Karger AG, Basel

\begin{abstract}
Addiction is a debilitating condition that extracts enormous social and economic tolls. Despite several decades of research, our knowledge of its etiology, preventive measures, and treatments is limited. A relatively recent research field with the potential to provide a more holistic understanding, and subsequently treatments, takes a phylogenetic view of addiction. This perspective is based on deep homologies at the genetic, proteomic, and behavioral levels, which are shared across all metazoan life; particularly those organisms faced with plant secondary metabolites as defensive compounds against insect herbivory. These addictive alkaloids, such as nicotine, cocaine, or cathinone, are commonly referred to as "human drugs of abuse" even though humans had little to no role in the co-evolutionary processes that determined their initial emergence or continued selection. This commentary discusses the overwhelming homologies of addictive alkaloid effects on neural systems across a wide range of taxa, as we aim to develop a broader comparative view of the "addicted brain." Taking nicotine as an example, homologous physiological responses to this compound identify
\end{abstract}

\section{Introduction}

Substance use disorder (SUD), or "addiction" in its severest form, is a debilitating and chronic brain disorder with an enormous social and economic toll. Manifesting as compulsive search for and consumption of a substance despite negative consequences, it is mediated by longlasting changes in neural connectivity, particularly in those brain regions implicated in learning and memory, decision making, and behavioral control [American Psychiatric Association, 2017]. The past 3 decades have yielded significant insights into the pathophysiology of this disorder. Leveraging animal models of SUD, differentially modifying specific neuronal subsets in targeted brain regions, and confirming results with human imaging studies, we have now gained some insight into what changes occur during initial exposure to a drug, and what mechanisms are damaged for addiction to take hold. However, the etiology of this disorder is not yet fully un- karger@karger.com

www.karger.com/bbe

(c) 2021 S. Karger AG, Basel

Karger ${ }^{\prime}=$
Moira J, van Staaden

Department of Biological Sciences

Life Sciences Building, Bowling Green State University

Bowling Green, OH 43403 (USA)

mvs.bgsu@gmail.com 
derstood, in part because of its multifactorial nature; with genetics, early familial and social stressors, trauma, social factors, and epigenetics, all contributing to the development of an addicted brain [National Institute on Drug Abuse, 2020]. The literature on drug addiction is predominantly mammalian as it had long been considered a human (or perhaps primate)-specific phenomenon, arising from the complex cognitive functions that define the "sapient" species [van Staaden et al., 2018]. In addition, the economic toll and desire for therapeutic medications led to a simplistic view of SUD, focused mainly on the receptors and pharmacology of the target substances. This conceptual approach led to the continued search for agonists and antagonists to combat drug overdose, and to help with cessation, withdrawal symptoms, and relapse prevention [Douaihy et al., 2013]. The true limits to our understanding of the causal and neural mechanisms underlying this complex disorder are on full display when we consider the dearth of effective preventative measures or treatments. With such a profound lack of understanding, human societies have repeatedly descended into drug use and overdose deaths at epidemic proportions, including the crack cocaine epidemic of the 1980s and 1990s, heroin in the late 1990s, and a wide range of new classes of synthetic opioids which are seeding future epidemics [Chen et al., 2019]. The comparative view of addictive processes originated with Nesse [1994]. The emergence of this field is based on overwhelming evidence of deep homologies across metazoan life at the genetic level $[\mathrm{Wu}$ et al., 2014], as well as in neuronal signaling pathways from receptors, neuromodulators, to neurotransmitters [Barron et al., 2010; Pandey et al., 2013; Katz and Lillvis, 2014], which ultimately generate behavior [Egnor and Branson, 2016]. This deep homology then translates into consistent responses and vulnerabilities at both the molecular and behavioral levels.

\section{Addictive Alkaloids as Defensive Compounds against Insect Herbivory}

Since their origin in the Ordovician 470 million years ago, sessile plants evolved effective solutions to deter the onslaught of fungi, bacteria, viral, and herbivorous predators [Wink, 1988]. Plant secondary metabolites (PSMs) comprise a vast array of metabolically expensive compounds with limited vital functions in the primary life of plants. A common hypothesis assigns to many substances in this group significant roles in adaptation to environmental and stressful constraints, preventing insect her- bivory, protecting against infection, and many other functions [Wink, 2003]. The precise structures of PSMs, individually and in combination, have been shaped over eons of selection to optimize their impact on neuronal processes, metabolism, and reproduction of herbivores. Examples of general structures among PSMs include amines, glucosinolates, terpenoids, phenolics, non-protein amino acids, quinones, flavanoids, and alkaloids. Depending on the specific need in deterring insect herbivory, PSMs with different structures may work synergistically and interfere with multiple, susceptible molecular target mechanisms [Mason and Singer, 2015]. This created an ongoing evolutionary arms race between plants and insects. As part of their defense mechanism, plants evolved neurotransmitter mimicking compounds which interfere with the nervous system function of their insect predators [Wink, 2000]. Herbivores feeding on plants with PSMs exerting several effects on their central nervous system (e.g., stimulants, hallucinogenics, psychedelics) will become incapacitated, experience altered perception of their metabolic needs, and suffer reduced fitness. Given the deep homology in neuronal function that exists across all bilateral metazoan animals, neural function in humans shares a vulnerability to these PSMs. Thus, our susceptibility to addiction might be viewed as little more than collateral damage in an epic battle waged between plants and insects.

\section{PSMs as Weaponized Learning Disruptors in Motivational Systems and Reward Circuitry}

It is safe to say that alkaloids are the most extensively studied PSMs in terms of addiction. Addictive alkaloids exert their effects through interfering with mechanisms of reward (opioids), or with motivation and active search (psychostimulants). The human endogenous opioid system involves 30 different neuroactive peptides and cognate G-protein-coupled receptors, widely distributed throughout the body, though concentrated in the central nervous system. Whereas the endogenous opioid system is best known for modulating pain perception, its widespread distribution in the brain indicates more diverse neuronal functioning [Pasternak and Pan, 2013]. The opioid system is ubiquitous in the hippocampus, a brain structure crucial for learning and memory, most notably contextual memory. Hippocampal exposure to exogenous opioids has been extensively studied and is thought to be a key mediator of the addictive properties of these substances, particularly in terms of contextual learning 
and memory [Klenowski et al., 2015]. The combination of inherent pain-modulatory and rewarding properties creates an abnormally robust memory linked to opioid exposure, an effect also reflected in the enhanced incentive salience experienced with chronic use of opioids and other addictive drugs. At the same time, deficits in retrograde-anterograde recall with chronic use have also been documented [Kamboj et al., 2005].

After administration of just a single dose, opioids exert significant effects on reward-based decision and cognitive control, mainly by modifying learning mechanisms and motivational processing. Studies in rodent models reveal impairments in response inhibition and sustained attention, suggesting that opioid administration impairs executive functioning and concentration [Jacobson et al., 2018]. With respect to reward-based decision-making, fMRI studies show modest evidence that opioids mediate the pleasure associated with rewards independent of a decision context. Concordant evidence from such human and rodent studies point to the involvement of the endogenous opioid system in reward learning and the motivation value in decision making about high-value stimuli [Chelnokova et al., 2014; Buchel et al., 2018]. Rodent studies and preliminary human studies show limited or no effects of opioid blockade on impulsivity [Kieres et al., 2004; Pattij et al., 2009; Weber et al., 2016]. Moreover, studies using opioid agonists demonstrate impaired logical reasoning and coding, with no effect on working memory (for a detailed review, see van Steenbergen et al. [2019]). Opioids are thought to mediate their effects on learning and memory pathways, forming pathways for addiction through their effects on neurogenesis. In particular, opioids modulate neuronal stem and progenitor cell proliferation, differentiation, and maturation, as well as adult neurogenesis particularly in the hippocampus (for a detailed review see Kibaly et al. [2019]).

One extensively studied mechanism through which alkaloids exert their addictive effects is through interfering with motivation and active search, a dopamine-dominant mechanism. For instance, psychostimulants such as cocaine and methamphetamine are well-known for their performance-enhancing properties. They improve attention, alertness, and cognition through catecholamines, particularly dopamine and serotonergic activation. At high doses, psychostimulants, methamphetamine in particular, induce their neurotoxic effects by damaging dopaminergic and serotonergic terminals, inducing apoptosis in neurons, and activation of microglia and astroglia in the nervous system. These effects are thought to be mediated by inducing oxidative stress in neurons, excitotox- icity, and the breakdown of the blood brain-barrier (for a more detailed review, see Cadet and Krasnova [2009]). Administration of toxic doses of methamphetamines trigger the activation of programmed cell death pathways as evidenced by the significant increase of the pro-death B-cell lymphoma 2 (Bcl-2) family of genes, BID, BAX, and $\mathrm{BAD}$ genes, and decrease of anti-death genes Bcl-2 and Bcl-XL [Jayanthi et al., 2001]. It should be noted that opioids exert similar effects on programmed cell death at high doses, although these effects have not been thoroughly investigated (for a more detailed review, see Cunha-Oliveira et al. [2008]). Psychostimulants are similarly well known for their addictive properties [Boutrel and Koob, 2004], and a vast literature attests to the cognitive deficits induced by these substances. This heterogeneity in the reaction to psychostimulants results, in part, from individual differences among users, but is primarily a dose-dependent effect. Depicting the common cognitive effect of psychostimulants would present as an inverted U-shape curve. Low doses of psychostimulants lead to arousal and cognitive enhancement, moderate doses lead also to cognitive improvement, a sense of power and euphoria, and high doses lead to psychosis, cognitive impairment, and circulatory collapse (for a detailed review, see Wood et al. [2013]).

Insects that consume psychostimulants become hyperactive, lose crypsis, and are more readily detected by predators. The point at which they lose the evolutionary arms race is when they can no longer reduce their sensitivity without detrimental effects to the seeking system. Thus, the Achilles heel of animals resides in the tradeoffs required for efficient learning, balancing specificity with generalization, and computational speed with behavioral flexibility. Addictive alkaloids commandeer neural drivers for motivated search and dysregulate the circuits for reward perception. The very nature of this interference limits the evolution of effective countermeasures. Inevitably, mutations that lessen an individual's sensitivity to these defenses are also accompanied by reduced initiative, lowered reward perception, and critically impaired decision-making.

Whereas we now have a robust understanding of how alkaloids interfere with learning, memory, and reward circuits, our understanding of prevention and intervention measures is far less well developed. Rather than address the issue of addiction and the associated cognitive and reward circuitry deficits directly, available treatments for drug addiction tend only to alleviate some of the withdrawal symptoms. Better understanding of the pathophysiology, etiology, and potential treatments for sub- 
stance abuse can be inferred by investigating drug effects in various animal models and dissecting the molecular effectors that would yield different treatment strategies. Next, we will illustrate the value of adopting a phylogenetic and comparative approach, rather than viewing addiction as an exclusively primate phenomenon, by considering one alkaloid that has been extensively studied in a variety of animal models and exploring homologies in their reaction to the same compound.

\section{Multi-Step Adaptive Walks and Comparative Analysis}

Exploring adaptive evolutionary change is a challenging task, and "just-so-stories" have frequently substituted for in-depth analyses [Gould et al., 1979]. Recently, the first in vivo validation of a multi-step adaptive walk in a multicellular organism showed that substitutions at 3 amino acid sites in the sodium pump $\alpha$-subunit (together, but not alone) enabled monarch butterflies to cope with the complex milieu of cardiac glycosides encountered during host shifts to milkweed [Karageorgi et al., 2019]. By introducing these genotypes into Drosophila using CRISPR-Cas9, Karageorgi et al. [2019] demonstrated at the organismal, physiological, and biochemical levels that the flies also develop target-site insensitivity and resistance to cardiac glycosides. This elegant work illustrates the possibilities now available to those interested in exploring the origins and impacts of addictive alkaloids.

One particular alkaloid with which humans have a long history is nicotine, a tertiary amine found naturally in plants of the Solanaceae family [Gebhardt, 2016]. Present in high concentrations in tobacco leaves, nicotine is thought to be a key contributor to tobacco addiction, a major preventable cause of disease worldwide. In the USA alone, half a million people die prematurely every year from heart and lung disease, cancer, and increased susceptibility to infectious agents, caused by smoking or exposure to secondhand smoke [US Department of Health and Human Services, 2004] and around USD 170 billion are spent on medical care associated with smoking-related diseases [Centers for Disease Control and Prevention, 2020]. We present nicotine here as an example of the value of comparative analysis, and in Figure 1 summarize the behavioral and molecular impacts of nicotine in studies of humans and model organisms, from Drosophila to non-human primates.

Nicotine binds to nicotinic cholinergic receptors (nAChRs) in both the central and peripheral nervous sys- tems [Fagerström, 2014]. These receptors are endogenously activated by acetylcholine, mediate learning and memory, reward and psychomotor behavior [Changeux, 2010], and play a crucial role in synaptogenesis, neuronal differentiation, and growth [Liu et al., 2007; Abreu-Villaça et al., 2011]. The neuronal subunits comprising mammalian nAChRs are diverse, with the $\alpha_{4} \beta_{2}$ subtype most ubiquitously expressed in the human brain, likely the main contributor to nicotine dependence [Gotti et al., 2006]. Brain imaging studies indicate that several regions in the cortico-basal ganglia-thalamic circuits show increased activity on nicotine consumption [Benowitz, 2009]. This is thought to be mediated by the release of several neurotransmitters, predominantly dopamine, upon activation of nAChRs in these brain regions. One pathway that has been extensively studied for its role in mediating drug reward and the subsequent development of nicotine dependence is the midbrain ventral tegmental area (VTA) and the release of dopamine in the nucleus accumbens shell [Dani and De Biasi, 2001; Nestler, 2005]. Nicotine's effect on the brain is however not limited to dopamine. Other neurotransmitters, including serotonin, endorphins, GABA, glutamate, acetylcholine, and norepinephrine, have been shown to mediate both the acute and chronic effects of nicotine consumption [Salas et al., 2003].

The strong reinforcing effect of nicotine exposure is aptly demonstrated in a study of non-human primates which was pivotal in showing behavioral responses mirroring that of humans [Le Foll et al., 2007]. Five naïve squirrel monkeys were permitted to self-administer nicotine intravenously via a choice of 2 levers. Within little more than a week, the monkeys developed a strong preference for the active (nicotine) over the inactive (control) lever, lever-pressing up to 600 times in their quest for a single nicotine injection. Subsequent studies using positron emission tomography demonstrated the release of dopamine after intravenous administration of nicotine [Marenco et al., 2004], and depression of this release in the nucleus accumbens with chronic nicotine exposure, an effect attributed to the action of the $\alpha_{6} \beta_{2}{ }^{*}$ nAChR subtype [Perez et al., 2012].

Dopamine mediation of nicotine response has been extensively studied in rodents. Using an intracranial selfstimulation model of reward, nicotine application significantly lowered, and withdrawal significantly increased, the threshold for self-stimulation [Epping-Jordan, 1998; Cryan et al., 2003]. Strong evidence from studies using mice self-administration shows a consistent role of the $\alpha_{4} \beta_{2}$ nAChR subtype in mediating the rewarding effects 


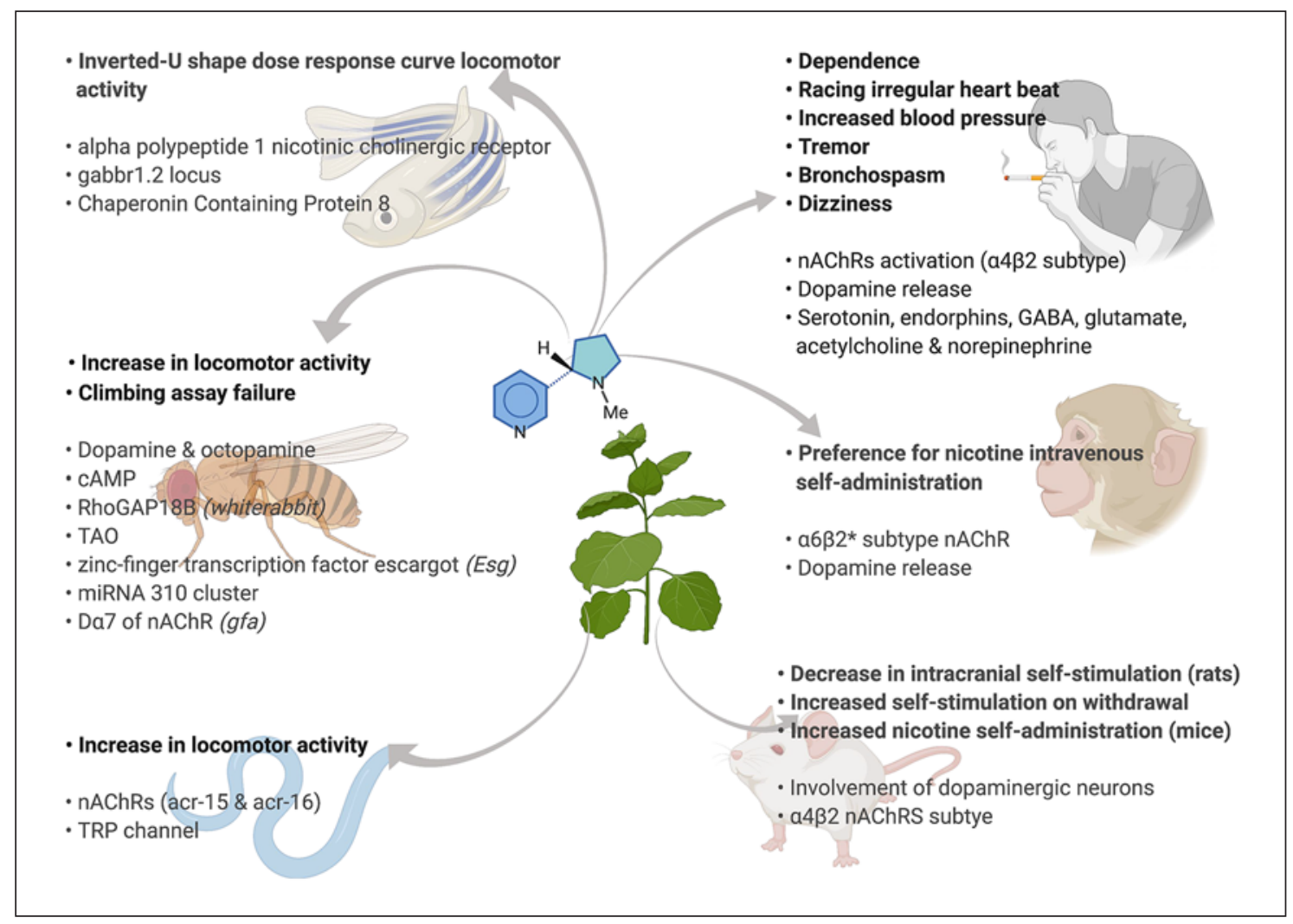

Fig. 1. Behavioral and molecular outcomes of nicotine consumption in humans and model organisms, including various rodents and non-human primates, zebrafish, C. elegans, and Drosophila. Nicotine binds to nicotinic cholinergic receptors (nAChRs). cAMP, adenosine $3^{\prime}, 5^{\prime}$-cyclic monophosphate; RhoGAP18b, Rho
GTPase-activating protein at 18b; TAO, thromboangiitis obliterans; miRNA 310 cluster, microRNA 310 cluster; TRP, transient receptor potential; GABA, gamma aminobutyric acid. (Created with BioRender.com.) of nicotine [Picciotto et al., 1998]. Whereas $\beta_{2}$-subunit gene knockout mice show no increase in self-administration and their mesencephalic dopaminergic neurons were unresponsiveness to nicotine, reinserting the subunit gene in the VTA restored responsiveness to nicotine [Maskos et al., 2005]. Similarly, studies of the $\alpha_{4}$-subunit show an equally important role in responsiveness and sensitivity to nicotine. Interestingly, a single nucleotide mutation in the pocket region of the receptor renders it hypersensitive to nicotine, generating increased behavioral response and tolerance [Tapper et al., 2004]. Hence, evidence from rodent experimental models point to a key role of the $\alpha_{4} \beta_{2}$ nAChR subtype and dopamine release in nicotine-mediated reward.

A similar role of dopaminergic pathways in mediating the effects of nicotine is evident in flies. Given that flies are responsive to ethanol, cocaine, caffeine, and amphetamines, it comes as no surprise that they are also acutely responsive to nicotine. In a climbing assay, flies treated with nicotine show impaired activity which is reversed by dopamine depletion [Bainton et al., 2000]. Dopaminergic pathways are not the sole contributor to the acute effects of nicotine in flies. Using the same assay, important roles of specific nAChR activation leading to octopamine release [Fuenzalida-Uribe et al., 2013], cAMP pathway [Hou et al., 2004], RhoGAP18B encoded by white rabbit [Rothenfluh et al., 2006], TAO, zinc-finger transcription factor escargot encoded by Esg mediating the acute effects of nicotine in flies [King et al., 2011] have been identified. Genetic lines screening for nicotine-induced hyperactivity revealed a similar role for the miRNA 310 cluster [Sanchez-Díaz et al., 2015] and $\mathrm{Da}_{7}$ of nAChR encoded by $g f a$ [Velazquez-Ulloa, 2017] in nicotine sensitivity.

The conserved role of $\mathrm{nAChRs}$ in mediating the effects of nicotine is evident in a Caenorhabditis elegans model of nicotine-dependent behavior. On exposure to nicotine, the behavioral responses of $C$. elegans resemble those observed in vertebrates, including acute locomotor effects, 
tolerance, sensitization, and withdrawal. Compared to naïve worms, those acutely exposed to nicotine exhibit a dose-dependent increase in activity. Chronic treatment produces adaptation, and nicotine cessation leads to withdrawal responses. Treatment with a nAChR competitive antagonist halted the acute response to nicotine, indicating a conserved role of nAChRs (acr-15 and acr-16). Interestingly, the transgene expression of mouse $\alpha_{4} \beta_{2}$, particularly in the acr-16 mutant background under the acr-16 promoter, rescued the mutant phenotype. Perhaps most important is the discovery of a novel role of transient receptor potential channels in this phenotype, with a potential role in humans as well [Feng et al., 2006].

Bringing this evolutionary comparison full circle, zebrafish provide insight on the conserved responsiveness to nicotine at both the behavioral and molecular levels. In an elegant study, locomotor activity following treatment with nicotine showed an inverted $U$-shaped dose response curve, similar to that observed in rodents, with high nicotine doses resulting in reduced activity [Petzold et al., 2009]. Consistent with other experimental models, zebrafish showed sensitization, locomotor activation was blocked by pretreatment with the non-selective, noncompetitive $\mathrm{nAChR}$ antagonist Mecamylamine, and fish with an alpha polypeptide $1 \mathrm{nAChR}$ mutation exhibit reduced responsiveness to nicotine. Using gene-breaking transposon mutagenesis, researchers applied a forward genetic screen to identify novel contributors to nicotine responsiveness in zebrafish, which could then be further investigated in other organisms. This led to the identification of Chaperonin Containing Protein 8 (cct8), an evolutionarily ancient gene with one human ortholog, and the gabbr1.2 locus, encoding one zebrafish ortholog of the GABA(B) receptor 7-pass transmembrane subunit 1 [Petzold et al., 2009]. Remarkably, there is evidence of a mammalian cct8 role in the nicotine response, cct8 mRNA levels are upregulated in the prefrontal cortex of rats following nicotine exposure [Li et al., 2003], and genetic variation in the GABA(B) receptor subunit 2 has been associated with nicotine dependence [Beuten et al., 2005].

\section{Conclusion}

Taxa for which some aspect of drug-reward has been reported trace the origin of the phenomenon to at least 950 million years ago. Over this vast time frame there can be, of course, no unitary explanation for the pathophysiology of all drugs of abuse, including psychostimulants, opioids, cannabinoids, and ethanol. How palatable one finds the comparative framework will likely depend on the particular substance investigated, the relative selective forces at play in the favored model system, and the relative importance of adaptive and non-adaptive forces of genetic drift and mutation in a given evolutionary pathway. Regardless of where one lands on these various axes, an evolutionary perspective is useful in directing the way in which we frame our questions. In the public sphere it is debatable which of the 2 terms, evolution or addiction, generates more heat. However, we propose that in the academic space of addiction researchers at least, it is the combination that will almost certainly generate more light.

\section{Conflict of Interest Statement}

The authors have no conflicts of interest to declare.

\section{Funding Sources}

M.J.v.S. was supported by a grant (DUE 1525623) from the National Science Foundation (NSF) during the preparation of this manuscript. The NSF played no further role in this work.

\section{Author Contributions}

Both listed authors made a substantial and direct contribution to the conception, design, illustration, and writing of the paper.

\section{References}

Abreu-Villaça Y, Filgueiras CC, Manhães AC. Developmental aspects of the cholinergic system. Behav Brain Res. 2011 Aug;221(2):367-78.

American Psychiatric Association. Addiction and substance use disorders: what is addiction? 2017. Accessed from: https://www.psychiatry.org/patients-families/addiction/what-isaddiction.
Bainton RJ, Tsai LT, Singh CM, Moore MS, Neckameyer WS, Heberlein U. Dopamine modulates acute responses to cocaine, nicotine and ethanol in Drosophila. Curr Biol. 2000 Feb; 10(4):187-94.

Barron AB, Søvik E, Cornish JL. The roles of dopamine and related compounds in rewardseeking behavior across animal phyla. Front Behav Neurosci. 2010 Oct;4:163.
Benowitz NL. Pharmacology of nicotine: addiction, smoking-induced disease, and therapeutics. Annu Rev Pharmacol Toxicol. 2009;49(1):57-71.

Beuten J, Ma JZ, Payne TJ, Dupont RT, Crews KM, Somes G, et al. Single- and multilocus allelic variants within the $\mathrm{GABA}(\mathrm{B})$ receptor subunit 2 (GABAB2) gene are significantly associated with nicotine dependence. Am J Hum Genet. 2005 May;76(5):859-64. 
Boutrel B, Koob GF. What keeps us awake: the neuropharmacology of stimulants and wakefulness-promoting medications. Sleep. 2004 Sep;27(6):1181-94.

Brody AL. Functional brain imaging of tobacco use and dependence. J Psychiatr Res. 2006 Aug;40(5):404-18.

Buchel C, Miedl S, Sprenger C. Hedonic processing in humans is mediated by an opioidergic mechanism in a mesocorticolimbic system. eLife. 2018 Nov;7:e39648.

Cadet JL, Krasnova IN. Molecular bases of methamphetamine-induced neurodegeneration. Int Rev Neurobiol. 2009;88:101-19.

Centers for Disease Control and Prevention. Smoking and tobacco use: data and statistics. Atlanta: CDC; 2020. https://www.cdc.gov/tobacco/data_statistics/index.htm.

Changeux JP. Nicotine addiction and nicotinic receptors: lessons from genetically modified mice. Nat Rev Neurosci. 2010 Jun;11(6):389401.

Chelnokova O, Laeng B, Eikemo M, Riegels J, Løseth G, Maurud H, et al. Rewards of beauty: the opioid system mediates social motivation in humans. Mol Psychiatry. 2014 Jul;19(7) 746-7.

Chen Q, Larochelle MR, Weaver DT, Lietz AP, Mueller PP, Mercaldo S, et al. Prevention of Prescription Opioid Misuse and Projected Overdose Deaths in the United States. JAMA Netw Open. 2019 Feb;2(2):e187621-187621.

Cryan JF, Bruijnzeel AW, Skjei KL, Markou A. Bupropion enhances brain reward function and reverses the affective and somatic aspects of nicotine withdrawal in the rat. Psychopharmacology (Berl). 2003 Jul;168(3):347-58.

Cunha-Oliveira T, Rego A, Oliveira C. Cellular and molecular mechanisms involved in the neurotoxicity of opioid and psychostimulant drugs. Brain Res Rev. 2008 Jun;58(1):192208

Dani JA, De Biasi M. Cellular mechanisms of nicotine addiction. Pharmacol Biochem Behav. 2001 Dec;70(4):439-46.

Douaihy AB, Kelly TM, Sullivan C. Medications for substance use disorders. Soc Work Public Health. 2013;28(3-4):264-78.

Egnor SE, Branson K. Computational analysis of behavior. Annu Rev Neurosci. 2016 Jul;39(1): $217-36$.

Epping-Jordan MP, Watkins SS, Koob GF, Markou A. Dramatic decreases in brain reward function during nicotine withdrawal. Nature. 1998 May;393(6680):76-9.

Fagerström K. Nicotine: pharmacology, toxicity and therapeutic use. J Smok Cessat. 2014;9(2): 53-9.

Feng Z, Li W, Ward A, Piggott BJ, Larkspur ER, Sternberg PW, et al. A C. elegans model of nicotine-dependent behavior: regulation by TRP-family channels. Cell. 2006 Nov;127(3): 621-33.

Fuenzalida-Uribe N, Meza RC, Hoffmann HA Varas R, Campusano JM. nAChR-induced octopamine release mediates the effect of nicotine on a startle response in Drosophila me- lanogaster. J Neurochem. 2013 Apr;125(2): 281-90.

Gebhardt C. The historical role of species from the Solanaceae plant family in genetic research. Theor Appl Genet. 2016 Dec;129(12): 2281-94.

Gotti C, Zoli M, Clementi F. Brain nicotinic acetylcholine receptors: native subtypes and their relevance. Trends Pharmacol Sci. 2006 Sep; 27(9):482-91.

Gould SJ, Lewontin RC. The spandrels of San Marco and the Panglossian paradigm: a critique of the adaptationist programme. Proc $\mathrm{R}$ Soc Lond B Biol Sci. 1979 Sep;205(1161):58198.

Hou J, Kuromi H, Fukasawa Y, Ueno K, Sakai T, Kidokoro Y. Repetitive exposures to nicotine induce a hyper-responsiveness via the cAMP/ PKA/CREB signal pathway in Drosophila. J Neurobiol. 2004 Aug;60(2):249-61.

Jacobson ML, Wulf HA, Browne CA, Lucki I. Opioid modulation of cognitive impairment in depression. Prog Brain Res. 2018;239:1-48.

Jayanthi S, Deng X, Bordelon M, McCoy MT, Cadet JL. Methamphetamine causes differential regulation of pro-death and anti-death $\mathrm{Bcl}-2$ genes in the mouse neocortex. FASEB J. 2001 Aug; 15(10):1745-52.

Kamboj SK, Tookman A, Jones L, Curran HV. The effects of immediate-release morphine on cognitive functioning in patients receiving chronic opioid therapy in palliative care. Pain. 2005 Oct;117(3):388-95.

Karageorgi M, Groen SC, Sumbul F, Pelaez JN, Verster KI, Aguilar JM, et al. Genome editing retraces the evolution of toxin resistance in the monarch butterfly. Nature. 2019 Oct; 574(7778):409-12.

Katz PS, Lillvis JL. Reconciling the deep homology of neuromodulation with the evolution of behavior. Curr Opin Neurobiol. 2014 Dec;29: 39-47.

Kibaly C, Xu C, Cahill CM, Evans CJ, Law PY. Non-nociceptive roles of opioids in the CNS: opioids' effects on neurogenesis, learning, memory and affect. Nat Rev Neurosci. 2019 Jan;20(1):5-18.

Kieres AK, Hausknecht KA, Farrar AM, Acheson A, de Wit H, Richards JB. Effects of morphine and naltrexone on impulsive decision making in rats. Psychopharmacology. 2004 Apr; 173(1-2):167-74.

King I, Tsai LT, Pflanz R, Voigt A, Lee S, Jäckle H, et al. Drosophila tao controls mushroom body development and ethanol-stimulated behavior through par-1. J Neurosci. 2011 Jan; 31(3):1139-48

Klenowski P, Morgan M, Bartlett SE. The role of $\delta$-opioid receptors in learning and memory underlying the development of addiction. $\mathrm{Br}$ J Pharmacol. 2015 Jan;172(2):297-310.

Le Foll B, Wertheim C, Goldberg SR. High reinforcing efficacy of nicotine in non-human primates. PLoS One. $2007 \mathrm{Feb}$;2(2):e230.

Li MD, Ma JZ, Cheng R, Dupont RT, Williams NJ, Crews KM, et al.; Framingham Heart Study. A genome-wide scan to identify loci for smoking rate in the Framingham Heart Study population. BMC Genet. 2003 Dec;4 Suppl 1:S103.

Liu Z, Zhang J, Berg DK. Role of endogenous nicotinic signaling in guiding neuronal development. Biochem Pharmacol. 2007 Oct;74(8): $1112-9$.

Marenco S, Carson RE, Berman KF, Herscovitch $P$, Weinberger DR. Nicotine-induced dopamine release in primates measured with $[11 \mathrm{C}]$ raclopride PET. Neuropsychopharmacology. 2004 Feb;29(2):259-68.

Maskos U, Molles BE, Pons S, Besson M, Guiard BP, Guilloux JP, et al. Nicotine reinforcement and cognition restored by targeted expression of nicotinic receptors. Nature. $2005 \mathrm{Jul}$ 436(7047):103-7.

Mason PA, Singer MS. Defensive mixology: combining acquired chemicals towards defence. Funct Ecol. 2015;29(4):441-50.

National Institute on Drug Abuse. Drugs, brain, and behavior: the science of addiction. $\mathrm{NIH}$ 2020. Accessed from: https://www.drugabuse.gov/publications/drugs-brains-behavior-science-addiction/preface.

Nesse RM. An evolutionary perspective on substance abuse. Ethol Sociobiol. 1994;15(5-6): 339-48.

Nestler EJ. Is there a common molecular pathway for addiction? Nat Neurosci. 2005 Nov;8(11) 1445-9.

Pandey P, Mersha MD, Dhillon HS. A synergistic approach towards understanding the functional significance of dopamine receptor interactions. J Mol Signal. 2013 Dec;8(1):13

Pasternak GW, Pan YX. Mu opioids and their receptors: evolution of a concept. Pharmacol Rev. 2013 Sep;65(4):1257-317.

Pattij T, Schetters D, Janssen MC, Wiskerke J, Schoffelmeer AN. Acute effects of morphine on distinct forms of impulsive behavior in rats. Psychopharmacology. 2009 Aug;205(3): 489-502.

Perez XA, Ly J, McIntosh JM, Quik M. Long-term nicotine exposure depresses dopamine release in nonhuman primate nucleus accumbens. J Pharmacol Exp Ther. 2012 Aug;342(2): $335-44$.

Petzold AM, Balciunas D, Sivasubbu S, Clark KJ, Bedell VM, Westcot SE, et al. Nicotine response genetics in the zebrafish. Proc Nat Acad Sci USA. 2009 Nov; 106(44):18662-7.

Picciotto MR, Zoli M, Rimondini R, Léna C Marubio LM, Pich EM, et al. Acetylcholine receptors containing the beta2 subunit are involved in the reinforcing properties of nicotine. Nature. 1998 Jan;391(6663):173-7.

Rothenfluh A, Threlkeld RJ, Bainton RJ, Tsai LT, Lasek AW, Heberlein U. Distinct behavioral responses to ethanol are regulated by alternate RhoGAP18B isoforms. Cell. 2006 Oct; 127(1):199-211.

Salas R, Orr-Urtreger A, Broide RS, Beaudet A, Paylor R, Biasi MD (2003): The Nicotinic Acetylcholine Receptor Subunit a5 Mediates Short-Term Effects of Nicotine in Vivo. Mol Pharmacol. 2003 May;63(5):1059-66. 
Sanchez-Díaz I, Rosales-Bravo F, Reyes-Taboada JL, Covarrubias AA, Narvaez-Padilla V, Reynaud $\mathrm{E}$. The Esg gene is involved in nicotine sensitivity in Drosophila melanogaster. PLoS One. 2015 Jul;10(7):e0133956.

Tapper AR, McKinney SL, Nashmi R, Schwarz J, Deshpande P, Labarca C, et al. Nicotine activation of $\alpha 4^{*}$ receptors: sufficient for reward, tolerance, and sensitization. Science. 2004 Nov;306(5698):1029-32.

US Department of Health and Human Services. The Health Consequences of Smoking: A Report of the Surgeon General. Atlanta: Centers for Disease Control and Prevention (US); 2004. Accessed from: https://www.cdc.gov/ tobacco/data_statistics/sgr/50th-anniversary/index.htm. van Staaden MJ, Hall FS, Huber R. The Deep Evolutionary Roots of "Addiction". J Ment Health Clin Psychol. 2018;2(3):8-13.

van Steenbergen H, Eikemo M, Leknes S. The role of the opioid system in decision making and cognitive control: A review. Cogn Affect Behav Neurosci. 2019 Jun;19(3):435-58.

Velazquez-Ulloa NA. A Drosophila model for developmental nicotine exposure. PLoS One. 2017 May; 12(5):e0177710.

Weber SC, Beck-Schimmer B, Kajdi ME, Müller D, Tobler PN, Quednow BB. Dopamine D2/3- and $\mu$-opioid receptor antagonists reduce cue-induced responding and reward impulsivity in humans. Transl Psychiatry. 2016 Jul;6(7):e850.

Wink M. Plant breeding: importance of plant secondary metabolites for protection against pathogens and herbivores. Theor Appl Genet. 1988;75(2):225-33.
Wink M. Interference of alkaloids with neuroreceptors and ion channels. Stud Nat Prod Chem. 2000;21:3-122.

Wink M. Evolution of secondary metabolites from an ecological and molecular phylogenetic perspective. Phytochemistry. 2003 Sep; 64(1):3-19.

Wood S, Sage JR, Shuman T, Anagnostaras SG. Psychostimulants and cognition: a continuum of behavioral and cognitive activation. Pharmacol Rev. 2013 Dec;66(1):193-221.

Wu YC, Bansal M, Ramussen M, Herrero J, Kellis M. Phylogenetic identification and functional characterization of orthologs and paralogs across human, mouse, fly, and worm. bioRxiv. 2014. doi: https://doi.org/10.1101/005736. 